\title{
Is It So Early to Discard Phillips Curve as a Policy Guide? Insights from Bangladesh
}

\author{
Kazi Mezbah Uddin Ahamad* Noushin Farjana Huda Chowdhury Shakil Mahmood Shaon \\ Lecturer, Department of Economics, Mawlana Bhashani Science and Technology University, Tangail, \\ Bangladesh
}

\begin{abstract}
The famous economic idea that describes the inverse relationship between inflation and unemployment is Phillips curve. The usual trade-off relationship that inflation shares with unemployment has recently become questionable as the behavior of the Phillips curve across different economies appears to be baffling. This has made the relevance of including Phillips curve as a policy guide quite doubtful. Against this backdrop, the study attempts to examine the existence of Phillips curve in Bangladesh. Employing autoregressive distributed lag (ARDL) bound testing approach to cointegration, the study has observed that Phillips curve is indeed existent in Bangladesh with its usual trade-off relationship. The findings on Phillips curve are robust as the curve has been observed to be existent in different sampling period using the same theoretical and econometric arrangement. The findings bear a good deal of weight to the central bank in Bangladesh as, sooner or later, it may have to adopt inflation-targeting monetary approach to rein in the inflation persistence in the country.
\end{abstract}

Keywords: inflation, unemployment, Phillips curve, NAIRU, ARDL, bound testing, Bangladesh

DOI: $10.7176 / \mathrm{DCS} / 10-4-05$

Publication date: April $30^{\text {th }} 2020$

\section{Introduction}

The significance of Phillips curve is prominently apparent in the policy framework formulated by a modern inflation-targeting central bank. In a set-up of three-equation model which comprises of demand side, supply side and a monetary rule; a central bank chooses the optimal monetary policy that can stabilize the economy following a shock. Phillips curves are the supply side constraint a central bank has to face. These curves provide the central bank the combination of output (unemployment) and inflation for a given level of expected inflation. To be exact, a central bank can only pinpoint the economy along the Phillips curve it faces in a period (Carlin and Soskice 2014). Based on the constraint of Phillips curve and the loss function, a central bank can select its desired policy move to be accommodating or non-accommodating. MR and IS curve complete the picture. MR curve simply denotes the uniquely preferred unemployment-inflation combination on the given Phillips curve the central bank faces in a period. The tool the central bank deploys to achieve that specific unemployment (output)inflation combination is real interest rate. This is where the IS curve becomes vital which shows a negative relationship between output and real interest rate. Seemingly, the whole process of stabilization of an economy by a central bank following an economic shock is indeed closely connected to Philips curve. A study concerning the validity of the Philips curve for a given economy is thus of paramount importance.

In this study we examine whether Phillips curve does exist for the economy in Bangladesh as recently serious doubts have been cast regarding the existence of Phillips curve and its use as a policy guide (Eliasson 2001, Niskanen 2002, Reichel 2004). Furthermore, monetary base targeting as an approach of monetary policy is deemed questionable in Bangladesh as it gives rise to sustained volatility of money growth in the economy to exacerbate inflation persistence (Hossain 2015). Inflation targeting also produces better economic outcome in countries which implement independent domestic monetary policy (Mishkin 2000). So, sooner or later inflation targeting approach to monetary policy may be pursued by Bangladesh Bank. Studying the existence of Phillips curve in Bangladesh in an empirical arrangement is thus relevant and well-timed. The next two sections provide respectively a review of some past relevant literature and an overview of inflation-unemployment dynamics in Bangladesh. And, the remainder of the article proceeds as follows. Section IV specifies the model. Section V describes the data and the econometric technique employed in this study to estimate the model formulated in the previous section. Section VI analyses the results and section VII concludes the article.

\section{Literature Review:}

The negative relationship between unemployment and inflation is mainly the outcome of seminal work by Phillips (1958). The work is chiefly an empirical observation which later receives theoretical attention by Lipsey (1960), Samuelson and Solow (1970). Friedman (1968) contributes to a more refined version of Phillips curve or accelerationist Phillips curve in which he assumes expectations are formed adaptively. Triangle models to analyze inflation behaviour bear a resemblance to accelerationist Phillips curve (Taylor 2000).

New Keynesian Phillips curve and expectation augmented Phillips curve postulated by Phelps (1967) and Friedman share similarity in formulation. Also, estimates of such common Phillips curve do confirm about its 
existence i.e. it maintains the trade-offs between inflation and unemployment (Roberts 1995). Blanchard et al. (2015) also finds the usual Phillips curve relationship to be preserved in twenty countries for the period 19902014 and 2007-2014, but they observe that the slope of the Phillips curve has declined over time in most countries. Ball and Mazumder (2011) and Murphy (2018) also corroborate the fact that over the time Phillips curve has actually flattened in US. On the contrary, Gordon (2013 establishes by employing triangle model to analyses inflation behavior that the slope of Phillips curve has been stable in US and thus can be of assistance to the central bank (Fed) to derive NAIRU for achieving proper policy direction as to unemployment and inflation. Coibion and Gorodnichenko (2015) suggest that Phillips curve is a novel conceptual framework to understand the relationship between prices and macroeconomic conditions. Hooper et al. (2020) observe that both price and wage inflation have maintained the usual inverse relationship with unemployment in US in the period 1961-2018. But since, 1988 price Phillips curve has lost its robustness whereas wage inflation has been still evident and resilient. Sek et al. (2015) find oil price shock has a direct effect on domestic inflation in low oil dependent countries as opposed to high oil dependent countries where the effect is felt indirectly through other channels. Dritsaki and Dritsaki (2013) find a long run causal relationship between inflation and unemployment in Greece for the period 1980-2010. Shahbaz et al. (2012) finds the existence of Phillips curve both in short and long run in North Cyprus. Haider and Dutta (2012) using annual data over 1980-2009 observe that the trade-off between inflation-unemployment is evident in case of Bangladesh. But they rely on OLS estimation procedure to draw conclusion in this respect.

Theoretically, in the long run inflation and unemployment don't show the trade-off relationship like that of short-run. Unemployment rate which yields this kind of relationship is known as NAIRU (non-accelerating rate of unemployment). Recently, NAIRU has also been a subject of empirical scrutiny. Much of the investigation as to the existence of NAIRU produces results which are not in line with the theoretical claim of a vertical long-run Phillips curve. Sala (2003) covering a panel of EU countries finds that the long run trade-off is far off being vertical. In the long-run inflation and unemployment show a trade-off in the EU countries. Bhattarai (2016) also reports a long-run relationship between unemployment and inflation in OECD economies.

A good deal of researches also finds that Phillips curve is non-existent. Vermeulen (2017) finds no evidence of short-run trade-off between inflation and unemployment. In the long run the study finds a negative association between inflation and employment growth. Eliasson (2001) finds ambiguous results concerning Phillips curve in Australia, Sweden, while the Phillips curve in America appears to be linear and usual. Niskanen (2002) finds a no short-run Phillps curve to exist for US in the period 1960-2001. But in the long-run it shows in US, unemployment is a positive function of inflation. Riechel (2004) corroborates the findings of Niskanen (2002) by employing ARDL cointegration technique. The study is conducted with data of an array of industrialized economies along with the US over 1960-2001 to find the existence of short-run Phillips curve only for the US and Italy, whereas, the other 14 countries do not have a short-run Phillips curve. Only for the US a long run negative relationship between unemployment and inflation has been observed.

\section{Overview of Inflation and Unemployment in Bangladesh}

Historically, behaviour of inflation in Bangladesh can be characterized as persistent and volatile. Inflation steadily fell from a higher rate in the early 1980s to a moderate level in the 1990s. A linear trend line is attached to the inflation series in the Figure (b), which denotes a downward trend of the inflation over the whole period. During the 1990s inflation stayed at a tractable level but, started to rise from the 2005. Since 2005 CPI inflation has been pretty volatile and rising. Unemployment showed an upward trend over the whole period. The vertical distance between inflation and unemployment has increased over time, which apparently denotes a trade-off link between these two series. 


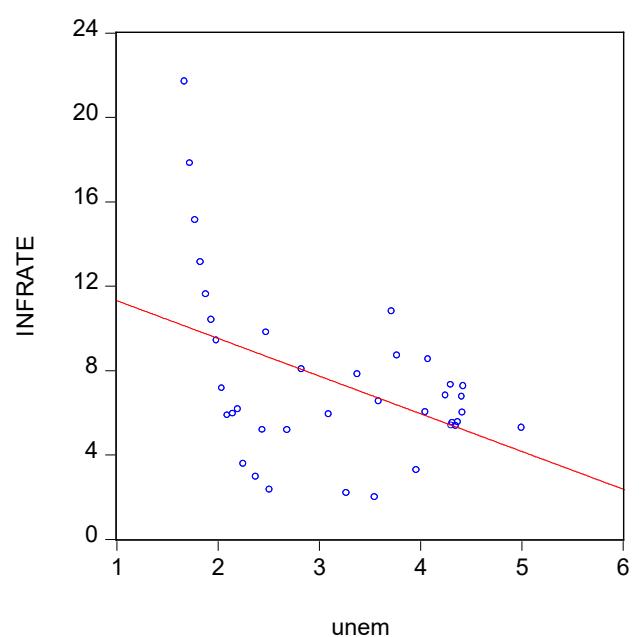

Figure (a) Inflation-Unemployment (1980-2018) Scatterplot

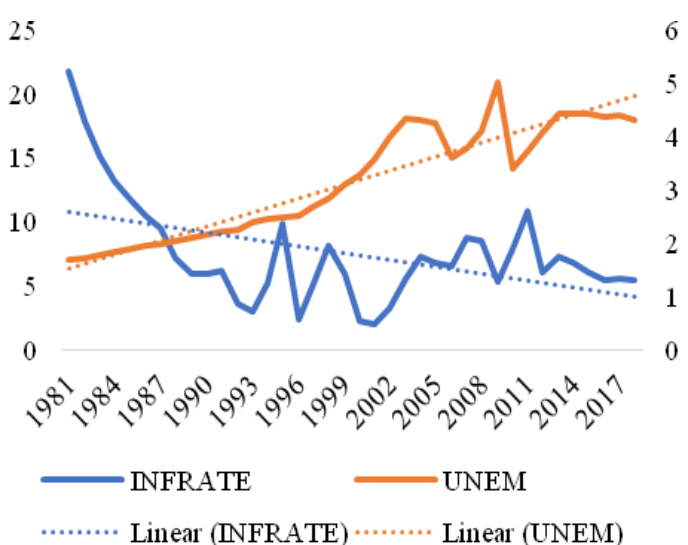

Figure (b) Overview of Inflation-Unemployment Series

A scatter plot concerning unemployment and inflation is also produced in Figure (a). A regression line is fit to get an idea on the association between unemployment-inflation with much simplicity. The fitted line also provides an indication about the trade-offs between unemployment-inflation over the whole period. The actual nature of relationship is examined in econometric framework in the later sections.

\section{Model Specification:}

Phillips curve in its modern form incorporates three crucial terms, such as, expected inflation, output gap or, cyclical unemployment and supply shocks (Mankiw 2016, Carlin and Soskice 2014). Based on this we can formulate a Phillips curve of the following form:

$$
\pi_{t}=\pi_{e}+\alpha\left(y_{t}-y_{e}\right)+v
$$

Here, $\pi$ denotes inflation and $\pi_{\mathrm{e}}$ denotes inflation expectations. Let, expectations are formed adaptively. Then we can write,

$$
\pi_{e}=\pi_{t-1}
$$

The coefficient of output gap indicates the slope of the Phillips curve. Output gap can also be expressed in terms of cyclical unemployment or the difference between the current unemployment rate and the equilibrium rate of unemployment following Okun (1962) Thus, the equation (1) can be rewritten as,

$$
\pi_{t}=\pi_{t-1}-\beta\left(u_{t}-u_{e}\right)+v
$$

One major difficulty concerning the equation (3) is the estimation of unobservable $u_{e}$ or, the NAIRU. Attempts have been made to estimate NAIRU using Kalman filter, Hodrick-Prescott filter or production function approach. But two problems may make the precision level of any such estimation of $u_{e}$ questionable: supply shocks and inconsistency of the NAIRU value over different period of time (Mankiw 2016). So, the equation (3) can be restated assuming $u_{e}$ constant following Eliasson (2001):

$$
\pi_{t}=\alpha+\pi_{t-1}+\beta u_{t}+v
$$

Where, $\alpha=\beta u_{e}$ and the a priori expectation regarding the coefficient $\beta$ is that it will be negative, indicating a trade-off between inflation and unemployment. Oil price proxies supply shocks $v$. It can be positive or negative depending upon the fluctuation in oil prices.

\section{Methodology and the Data}

We have employed ARDL (auto regressive distributed lag) bound testing approach (Pesaran and Shin 1995); (Pesaran and Pesaran (1997); (Pesaran et al. 2001) of cointegration to carry out the estimation process of equation. (3). Employing ARDL technique to discover cointegration or long-run relationship instead of conventional cointegration approach developed by Johansen (1998), Johansen and Juselius (1990), or Engle Granger (1987) has several advantages. Unlike the other approaches to testing for cointegration, ARDL bound testing technique doesn't require pre-testing of the variables for unit root to classify those into I(0) or I(1). The technique is applicable despite the variables are purely $\mathrm{I}(0)$ or $\mathrm{I}(1)$ or admixture of both. ARDL estimation procedure yields better results even in a smaller sample size as opposed to the Johansen cointegration approach that requires comparatively a bigger sample size. The approach can be accomplished in a single equation set-up 
whereas other methodology may require system of equations. Also, flexibility in assigning optimal lag value for different variables make the approach advantageous over other techniques.

Our data span the year 1980-2018. Data are annual; hence we have kept the maximum lag value at two following Pesaran and Shin (1998) and Narayan (2004). Then the optimal number of lags are selected based on the Schwarz info criterion (SIC) for sampling period 1980-2018 and Akaike info criterion (AIC) for sampling period 1991-2018.

Equation (3) is stated in the following ARDL form:

$$
\Delta \pi_{t}=\alpha+\sum_{i=1}^{k} \psi_{i} \Delta \pi_{t-i}+\sum_{j=0}^{l} \psi_{j} \Delta u_{t-j}+\sum_{m=0}^{n} \psi_{m} \Delta \operatorname{oilp}_{t-m}+\delta_{1} \pi_{t-1}+\delta_{2} u_{t-1}+\delta_{3} \text { oilp }_{t-1}+e_{t}
$$

Here, $e_{t}$ is the white noise term and $\Delta$ is the first difference operator. $\pi$ is the CPI inflation converted in natural logarithm, $u$ is the unemployment rate expressed in percentage value. WDI 2020 is the source of the CPI and unemployment data series. oilp is the natural logarithm of West Texas Intermediate (WTI) crude oil price. Data on WTI crude oil price is retrieved from Federal Reserve Economic Data.

Equation (5) commences the estimation procedure. To test for the existence of cointegration among variables joint F-statistic or Wald statistic is calculated. The null hypothesis in this test is $H_{o}: \delta_{1}=\delta_{2}=\delta_{3}=0$ against the alternative hypothesis of $H_{a}: \delta_{1} \neq \delta_{2} \neq \delta_{3} \neq 0$ implying cointegration or long run relationship among variables. The computed F-statistic is compared with two sets of F-statistic critical values namely, lower bound $\mathrm{F}_{\mathrm{L}}: \mathrm{I}(0)$ and upper bound $\mathrm{F}_{\mathrm{U}}$ : $\mathrm{I}(1)$. If computed F-statistic exceeds upper bound, null hypothesis is rejected to conclude that there is a long run relationship among variables. If computed F-statistic is lower than the lower bound $F_{L}$ then the null is not rejected to conclude that there is no long run relationship among the variables. In case, the computed F-statistic lies between these two bounds no conclusive decision can be made without knowing the order of integration of the underlying variables. If equation (5) yields a favorable result as to the existence of cointegration we estimate the following long run equation (6),

$$
\pi_{t}=\alpha+\sum_{i=1}^{a} \psi_{i} \pi_{t-i}+\sum_{j=0}^{b} \psi_{j} u_{t-j}+\sum_{m=0}^{c} \psi_{m} \text { oilp }_{t-m}+\eta_{t}
$$

And equation (7) provides short run dynamics.

$$
\Delta \pi_{t}=\alpha+\sum_{i=1}^{k} \psi_{i} \Delta \pi_{t-i}+\sum_{j=0}^{l} \psi_{j} \Delta u_{t-j}+\sum_{m=0}^{n} \psi_{m} \Delta o i l p_{t-m}+\phi E C T_{t-1}+\varepsilon_{t}
$$

Here, ECT is the error correction term and coefficient $\phi$ denotes the speed of adjustment. That is, how much of the disequilibrium in the past period gets corrected in the current period for the system to converge to the long run equilibrium. The coefficient should be negative and statistically significant.

\section{Results Analysis:}

Though ARDL approach to cointegration doesn't require the pretesting for the unit roots of the variables of interest, it is safe to run the tests in order to make sure that none of the underlying variables is $I(2)$. Presence of I(2) variables in the model will render the results spurious (Ahamad et al. 2019). We make use of augmented Dicky-Fuller (ADF) and Phillips-Perron unit root test to check the order of integration I(d) of the variables included in the model. Technical details regarding both tests are not repeated in this paper.

Table. 1

\begin{tabular}{ccccccc}
\hline \multicolumn{7}{c}{ Unit Root Test Results } \\
\hline \multirow{2}{*}{ Variables } & ADF & $\begin{array}{c}1 \% \text { Critical } \\
\text { Vtatistics }\end{array}$ & $\begin{array}{c}5 \% \text { Critical } \\
\text { Value }\end{array}$ & PP Statistics & $\begin{array}{c}1 \% \text { Critical } \\
\text { Value }\end{array}$ & $\begin{array}{c}5 \% \text { Critical } \\
\text { Value }\end{array}$ \\
\hline$\pi_{t}$ & -4.182396 & -3.615588 & -2.941145 & -4.960014 & -4.219126 & -3.533083 \\
$\Delta \pi_{t}$ & -4.090071 & -3.621023 & -2.943427 & -4.539245 & -3.621023 & -2.943427 \\
$u_{t}$ & -3.287961 & -4.219126 & -3.533083 & -3.290491 & -4.219126 & -3.533083 \\
$\Delta u_{t}$ & -7.487304 & -2.628961 & -1.950117 & -7.412208 & -2.628961 & -1.950117 \\
oilp $_{t}$ & -2.259306 & -4.219126 & -3.533083 & -2.259306 & -4.219126 & -3.533083 \\
$\Delta$ oilp & -6.046138 & -2.628961 & -1.950117 & -6.045978 & -2.628961 & -1.951000 \\
\hline
\end{tabular}

Care has been taken to include constant, constant and trend or, none of these two in the testing procedure to check for the unit roots of the underlying variables. Null hypothesis of the both unit root tests is "the time series is non-stationary or, presence of unit root in it" against the alternative of "the time series is stationary or, no unit 
root in the time series". Table. 1 contains the test results. Computed and critical ADF and PP-statistic at the $1 \%$ and 5\% level are attached in it. The results indicate that CPI inflation series is I(0) or, stationary at the level form. On the other hand, series of WTI crude oil price and unemployment rate series are I(1). Condition like this, where an admixture of $\mathrm{I}(0)$ and $\mathrm{I}(1)$ series is present in the model, renders ARDL error correction technique the most suitable one as the estimation technique.

As the unit root tests show existence of no I(2) series among the time series data considered in the study, we estimate equation (4) to check for the presence of cointegration or long run relationship among the variables. As, the data are annual, we have kept the maximum lag length at 2. Then the optimal number of lags are selected based on the Schwarz info criterion (SIC) for sampling period 1980-2018 and Akaike info criterion (AIC) for sampling period 1991-2018. The lag lengths that minimize SIC and AIC for both sampling period are ARDL $(2,2,2)$ for model 1 and ARDL $(1,1,2)$ for model 2. Table. 2 contains the test results on cointegration. As reported in the Table. 2, computed F-statistic for Model 1 involving time period 1980-2018 is 6.16849, which exceeds the upper bound critical value for finite ${ }^{1}$ sample size $n=40$ at the $10 \%$ level. That is for the Model 1 there exists a cointegration or long run relationship among the variables. Computed F-statistic for the Model 2 involving time period (1991-2018) also confirms that a long run relationship exists, as the competed $\mathrm{F}$ value exceeds the upper bound critical value for finite sample size $n=35$ at the $10 \%$ level. Both of the model also confirm that no ARCH effect is present in those and the error terms are normally distributed as indicated by insignificant Jarque-Bera (JB) test statistic in Table. 2.

Table. 2

F-Bounds Test to Cointegration

Upon having the confirmation regarding the existence of cointegration in both models we estimate the long run model stated in equation (4). We have estimated two long run models to check the robustness of the existence of Phillips curve in Bangladesh. Table. 3 reports the findings on the long run or level form equations. For the period 1980-2018 the coefficient of the unemployment rate turns out to be negative and significant at the $20 \%$ level. This denotes a long run trade-off between unemployment and inflation to be existent in Bangladesh. The same result is observed in the case of time period 1991-2018. The coefficient of unemployment rate is still negative but significant at the $10 \%$ level now. That is, in the long run the trade-off between unemployment and inflation also exists for the period 1991-2018. The coefficients of oil price turn out to be positive and significant at the 5\% and 10\% level for the period 1980-2018 and 1991-2018 respectively. The results imply that in the long run a unit increase in the oil price increases CPI inflation in Bangladesh by $0.136 \%$ and $0.08 \%$ for the period 1980-2018 and 1991-2018 respectively.

Table. 3

\begin{tabular}{ccc}
\hline \multicolumn{3}{c}{ Estimation Results of Long-run Equation } \\
\hline & Dependent Variable: log of CPI inflation $(\pi)$ & Sample $(1991-2018)$ \\
\hline$u_{t}$ & Sample $(1980-2018)$ & -0.12079 \\
& -0.06763 & $(-3.96703)^{\mathrm{a}}$ \\
oilp & $(-1.26475)^{\mathrm{d}}$ & 0.077334 \\
& 0.135745 & $(1.710762)^{\mathrm{c}}$ \\
trend & $(1.987184)^{\mathrm{b}}$ & 0.068545 \\
& & $(18.70762)^{\mathrm{a}}$ \\
\hline
\end{tabular}

Notes: a, b, c, d denote significant at the level 1\% or, below, $5 \%$ or, below, $10 \%$ or, below, $20 \%$ or, below respectively. In the parentheses, t-statistic is provided for the corresponding coefficient.

Apparently, the effect of an increase in oil price has a lower and a reduced influence on the increase in CPI inflation in Bangladesh in the period 1991-2018 compared with the whole period.

Short-run findings are presented in the Table. 4. This is of particular interest as it will provide a validation

\footnotetext{
${ }^{1}$ In this particular case critical values of F statistic developed by Narayan (2004) to analyze bound testing result should be used instead of FStatistic tabulated by Pesaran et al. (2001). Because Pesaran's F-Statistic seems to overestimate the presence of cointegration in small sample (30 observations to 80 observations) analysis.
} 
regarding the existence of short-run Phillips curve in Bangladesh. We have estimated two short-run equation for two different sampling period to make sure that the findings on Phillips curve are robust across different time span. In the period 1980-2018 most of the coefficients on the variables of interest register a significant and expected sign. The coefficient on unemployment rate is negative and significant at the $10 \%$ level to confirm that Phillips curve does exist in Bangladesh. That is, the short run trade-off between unemployment rate and inflation exists for the data of Bangladesh. Unemployment rate lagged by a period also turns out to be negative and significant. The short-run impact of oil price replicates the same findings found in the long-run. The estimated short-run coefficient on the oil price is highly significant and, but its short-run elasticity is very small. The coefficient on the error correction term, $E C T_{t-1}$ turns out to be highly significant and negative to confirm that the model converges to long-run equilibrium. The coefficient is -0.16918 indicating that a $16.91 \%$ disequilibrium in the previous period gets corrected in the current period.

To check the robustness of the findings on the existence of Phillips curve, we have estimated the Phillips curve using different sample period 1991-2018. The results are reported in the Table. 4. Here, the short-run coefficient of unemployment rate also turns out to be significant and negative to indicate that the Phillips curve is observable for the data of Bangladesh.

Here, the short-run coefficient of unemployment rate also turns out be significant and negative to indicate that the Phillips curve is observable for the data of Bangladesh. The results carry an important implication for the monetary policy makers in the country. The short run effect of oil price is low and insignificant in this period. The coefficient on the error correction term $E C T_{t-1}$ is highly significant and negative. The coefficient is -0.33894 indicating that in each period $33.89 \%$ of disequilibrium from the previous period gets adjusted to bring the system to long-run equilibrium.

Table. 4

\begin{tabular}{|c|c|c|}
\hline \multicolumn{3}{|c|}{ Estimation Results of Short-run Equation } \\
\hline & \multicolumn{2}{|c|}{ Dependent variable: $\log$ of CPI inflation } \\
\hline & Sample (1980-2018) & Sample (1991-2018) \\
\hline Independent Variable & & Coefficient \\
\hline 然 & $\begin{array}{c}0.478615 * * * \\
(4.733072)\end{array}$ & $\begin{array}{c}0.99464 * * * \\
(4.960803)\end{array}$ \\
\hline$\Delta \pi_{t-1}$ & $\begin{array}{c}0.214854 * * * \\
(1.844712)\end{array}$ & \\
\hline$\Delta u_{t}$ & $\begin{array}{l}-0.01296^{*} \\
(-1.59214)\end{array}$ & $\begin{array}{c}-0.01918^{* *} \\
(-2.09917)\end{array}$ \\
\hline$\Delta u_{t-1}$ & $\begin{array}{l}-0.01747^{*} \\
(-2.24368)\end{array}$ & \\
\hline$\Delta \operatorname{oilp}_{t}$ & $\begin{array}{c}0.001451 * * * \\
(0.129715)\end{array}$ & $\begin{array}{c}0.00533 \\
(0.387058)\end{array}$ \\
\hline$\Delta \operatorname{oilp}_{t-1}$ & $\begin{array}{c}-0.03072 \\
(-2.51236)\end{array}$ & $\begin{array}{l}-0.02889^{*} \\
(-1.86934)\end{array}$ \\
\hline trend & $\begin{array}{c}0.009928 * * * \\
(4.362247)\end{array}$ & \\
\hline$E C T_{t-1}$ & $\begin{array}{c}-0.16918 * * * \\
(-4.45828)\end{array}$ & $\begin{array}{c}-0.33894 * * * \\
(-4.66328)\end{array}$ \\
\hline
\end{tabular}

*** denotes significant at the $1 \%$ level or, below; ** denotes significant at the $5 \%$ level or; below; * denotes significant at the $10 \%$ level or, below

\section{Conclusion}

This study is conducted to examine the existence of the Phillips curve in Bangladesh. We have found the existence of Phillips curve for the data of Bangladesh. The findings are similar across different sampling period to draw a robust conclusion on the existence of Phillips curve in Bangladesh. A long-run trade-off between unemployment and inflation has been observed in both sampling period used in the study. This finding doesn't conform to the traditional theory on NAIRU but is in line with many past empirics. Important findings on oil price have also been observed in the study. Oil price positively influences the CPI inflation in Bangladesh in the long-run. For an inflation targeting central bank Phillips curve carries a good deal of weight as it works as a crucial policy guide. In Bangladesh the central bank pursues a monetary base targeting approach to reach certain economic outcome and to stabilize the economy following an economic shock. This approach to monetary policy contributes to the persistence of inflation in the country. So, sooner or later, the central bank may have to pursue inflation targeting policy to rein in the persistence of inflation in the country. This is where the confirmation regarding the existence of Phillips curve becomes vital and relevant. Moreover, regardless of the monetary-base targeting policy that the central bank pursues presently or, the inflation-targeting policy it may implement in the 
near future, it has to bear in mind that the classic trade-off link between inflation and unemployment has evidently been valid and present in Bangladesh. It's policy formulation to achieve certain economic goals such as achieving particular output and price level thus should take the usual Phillips curve relationship into consideration. So, it's safe to conclude that Phillips curve as a policy guide cannot be discarded anytime soon.

\section{References}

Ahamad, K. M. U. and Chowdhury, N. F. H. \& Muzib, M. 2019. "Aid-growth Nexus in Bangladesh: An Evidence from the ARDL Bound Testing Approach." Journal of Economics and Sustainable Development, 10(6) 10.7176/JESD/10-6-17.

Ball, L. and Mazumder, S. 2011. "Inflation Dynamics and the Great Recession," Brookings Papers on Economic Activity, Economic Studies Program, The Brookings Institution, vol. 42 (1): 337-405

Blanchard, O. and Cerutti, E. and Summers, L. 2015. "Inflation and Activity - Two Explorations and their Monetary Policy Implications," IMF Working Papers, vol 15(230).

Carlin, Wendy and Soskice, David. 2014. Macroeconomics: Institutions, Instability, and the Financial System, Oxford University Press, https://EconPapers.repec.org/RePEc:oxp:obooks:9780199655793.

Coibion, Olivier, and Yuriy Gorodnichenko. 2015. "Is the Phillips Curve Alive and Well after All? Inflation Expectations and the Missing Disinflation." American Economic Journal: Macroeconomics, 7 (1): 197-232.

Eliasson, A. 2001. "Is the Short-run Phillips Curve Nonlinear? Empirical Evidence for Australia, Sweden and the United States." Sveriges Riksbank Working Paper-124, Stockholm School of Economics, Department of Economic Statistics.

Engle, R. F. and C. W. J. Granger. 1987. "Cointegration and Error Correction: Representation, Estimation and Testing." Econometrica, 55(2): 251-276.

Federal Reserve Bank of St. Louis, Spot Crude Oil Price: West Texas Intermediate (WTI) [WTISPLC], retrieved from FRED, Federal Reserve Bank of St. Louis; https://fred.stlouisfed.org/series/WTISPLC, April 5, 2020.

Friedman, M. 1968. "The Role of Monetary Policy." American Economic Review, 58: 1-17.

Haider, M. Z. and Dutta, C. B. 2012. "Inflation-unemployment Trade-off: Evidence from Bangladesh Economy", Asia-Pacific Journal of Management Research and Innovation, 8(3) 227-237

Hooper, P. \& Frederic S. Mishkin \& Amir Sufi. 2020. "Prospects for Inflation in a High-Pressure Economy: Is the Phillips Curve Dead or is It Just Hibernating?" Research in Economics, 74 (1): 26-62

Johansen, S. 1998. Statistical Analysis of Cointegration Vectors. Journal of Economic Dynamics and Control. $12,231-254$.

Johansen, S., \& Juselius, K. 1990. Maximum Likelihood Estimation and Inference on Cointegration with Applications to the Demand for Money. Oxford Bulletin of Economics and Statistics. 52, 169-210.

Lipsey, R. G. 1960. "The Relation between Unemployment and the Rate of Change of Money Wage Rate in United Kingdom 1962 - 1951.” Economica, 27: 1-12.

Mankiw, N. Gregory author. 2016. Macroeconomics. New York: Worth Publishers

Mishkin, F. S. 2000. "From Monetary Targeting to Inflation Targeting: Lessons from the Industrialized Countries." Stabilization and Monetary Policy: The International Experience. Mexico City, November 14$15,2000$.

Murphy, A. 2018. "The Death of the Phillips Curve?” FRB of Dallas Working Paper No. 1801. Available at SSRN: https://ssrn.com/abstract=3125301 or http://dx.doi.org/10.24149/wp1801

Narayan, P. K. 2004. Reformulating Critical Values for the Bounds F-statistics Approach to Cointegration: An Application to the Tourism Demand Model for Fiji. Discussion Papers. Victoria: Department of Economics, Monash University.

Niskanen, W.A. 2002. "On the Death of Phillips Curve.” Cato Journal, 22: 193-98

Okun, A. M. 1962. "Potential GNP: Its Measurement and Significance," in Proceedings of the Business and Economics Statistics Section, American Statistical Association (Washington, DC: American Statistical Association, 1962): 98-103; reprinted in Arthur M. Okun, Economics for Policymaking (Cambridge, MA.: MIT Press, 1983), 145-158.

Pesaran, H. M. and Shin, Y. (1998) Autoregressive Distributed Lag Modelling Approach to Cointegration Analysis, in: Econometrics and Economic Theory in the 20th Century: The Ragnar Frisch Centennial Symposium, S. Storm (Ed.), chapter 11. Cambridge: Cambridge University Press.

Pesaran, H. M. et al. 2001. Bounds Testing Approaches to the Analysis of Level Relationships. Journal of Applied Econometrics. 16, 289-326.

Pesaran, H. M., \& Pesaran, B. 1997. Microfit 4.0. Oxford: Oxford University Press.

Pesaran, H. M., \& Shin, Y. 1995. Autoregressive Distributed Lag Modelling Approach to Cointegration Analysis. DAE Working Paper Series No. 9514 (Cambridge: Department of Applied Economics, University of Cambridge)

Phelps. E. 1967. "Phillips Curve, Expectation of Inflation, and Optimal Inflation over Time.” Economica, 34 : 
254-281.

Phillips. A.W. 1958. "The Relationship between Unemployment and the Rate of Change of Money Wage Rates in the United Kingdom." Economica, 25: 258-299.

Phillips. P. C. B and M. Loretan. 1991. "Estimating Long-Run Economic Equilibria." Review of Economic Studies, 58: 407-436.

Reichel. R. 2004. "On the Death of the Phillips Curve: Further Evidence." Cato Journal, 24: 341-348.

Roberts, J. M. 1995. "New Keynesian Economics and the Phillips Curve", Journal of Money, Credit and Banking, 27(4): 975-984

Samuelson, P. A. and R. M. Solow. 1960. “Analytical Aspects of Anti-inflation Policy.” American Economic Review, 5: 177-194.

Sek, S. K. and Xue Qi Teo and Yen Nee Wong. 2015. "A Comparative Study on the Effects of Oil Price Changes on Inflation" Procedia Economics and Finance, 26: 630-636

Taylor, J. 2000. "Teaching Modern Macroeconomics at the Principles Level." American Economic Review. 90 (2): $90-94$

Vermeulen, Cobus. 2017. "Inflation and unemployment in South Africa: Is the Phillips curve still dead?" Southern African Business Review, 21. 20-54.

World Bank. World Development Indicators 2020. 